
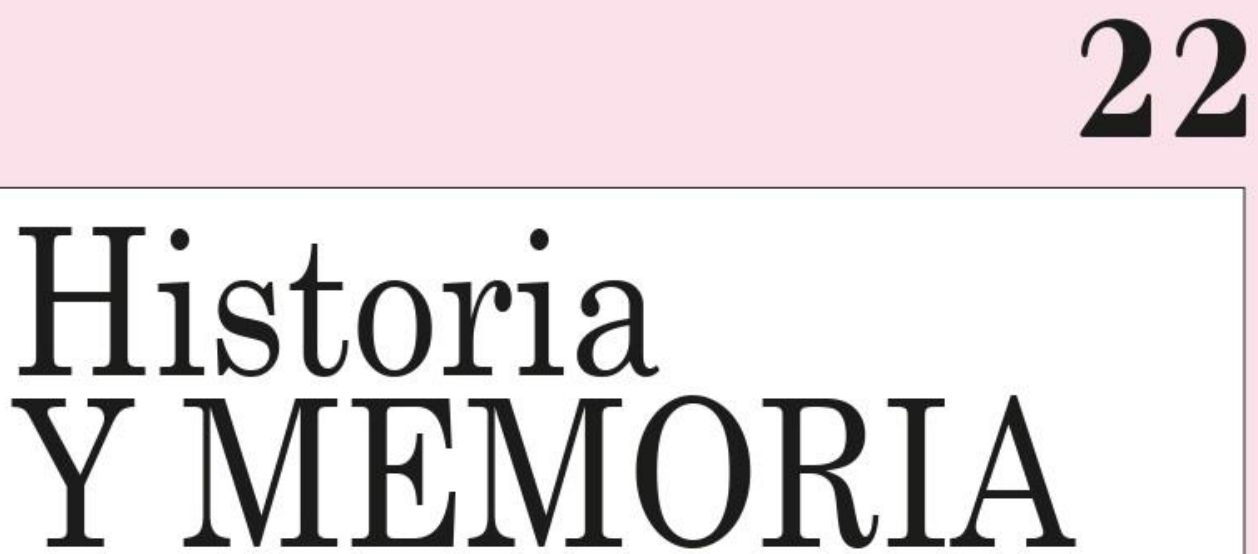

ISSN: 2027-5137

Enero - Junio, Año 2021 - Tunja, Colombia

Platería, perlas y negocios de la primera mitad del siglo XVI. Alonso de Oviedo y su protagonismo en la Sevilla americana y mercantil

https:/doi.org/10.19053/20275137.n22.2021.10988

Francisco Javier Herrera García Páginas 359-395

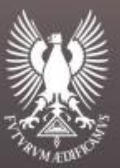




\title{
Platería, perlas y negocios en la primera mitad del siglo XVI. Alonso de Oviedo y su protagonismo en la Sevilla americana y mercantil*
}

\author{
Francisco Javier Herrera García ${ }^{1}$ \\ Universidad de Sevilla - España
}

Recepción: 09/05/2020

Evaluación: 03/07/2020

Aprobación: 02/09/2020

Artículo de Investigación e Innovación

https:/doi.org/10.19053/20275137.n22.2021.10988

\section{Resumen}

En el presente trabajo nos aproximaremos al complejo y dinámico contexto histórico de la Sevilla de la primera mitad del XVI, cuando la actividad comercial y financiera adquieren cotas nunca antes conocidas en Europa, gracias a las ingentes posibilidades de transacciones propiciadas por el Nuevo Mundo. Los protagonistas de aquel impulso vital, tanto españoles como de otros puntos de Europa, resultan

\footnotetext{
* Proyecto «Arte y comercio entre América y España durante el siglo XVI.» Grupo de investigación "Laraña» HUM317, financiado por la Consejería de Economía, Conocimiento, Empresas y Universidad. Junta de Andalucía.

1 Doctor en Historia del Arte por la Universidad de Sevilla, profesor en el Departamento de Historia del Arte de la Universidad de Sevilla. Publicaciones recientes: «De Sevilla al Nuevo Reino de Granada. Tomás Sánchez Reciente y su acomodada etapa santafereña (1753-1776),» en El Jardín de las Hespérides: Estudios sobre la plata en Iberoamérica. Siglos XVI al XIX, coord. Jesús Paniagua, Nuria Salazar y Jesús Pérez Morera (Ciudad de México: INAH; León: Instituto de Humanismo y Tradición Clásica, 2020), 111-135; «Panorama de la peinture murale en Andalousie occidentale au cours des XV et XVI siècles (espaces, iconographie, auteurs),» en Fresques de Corse et de Méditerranée occidentale. Sguardi incruciati / regards croisés (Bastia, Córcega-Francia: Collectivité de Corse; Éditions Éoliennes, 2020), 134-153. Rosario Halcón Álvarez-Ossorio y Francisco Javier Herrera García, «Primer Proyecto del Triunfo para la Beatificación de San Fernando: Bernardo Simón de Pineda y Juan de Valdés Leal (1671),» Archivo Español de Arte Vol. 93, n 370 (2020): 97-112.凶fjherrera@us.es (1) https://orcid.org/0000-0002-5032-5351.
} 
parcialmente conocidos. Día a día surgen nuevos ejemplos del prototipo de «hombre de negocios con Indias». Alonso de Oviedo, aquí analizado, ayuda a comprender con más amplitud el espacio temporal, humano y económico indicado. Su perfil sobrepasa las constantes habituales de esta tipología, pues añade a su dedicación mercantil, una actividad artística muy vinculada al desarrollo económico mencionado, como es el arte de la platería, también explorado en estas líneas. La relación con el negocio de perlas y aljófar encaja dentro de uno de los capítulos que mayor interés despertaron en la sociedad europea de la época, asociado al lujo y al misterio de los mares y tierras lejanas. La investigación parte de abundante documentación inédita procedente del Archivo General de Indias y Archivo Histórico Provincial, ambos de Sevilla.

Palabras clave: Alonso de Oviedo, Sevilla, Cubagua, Platería, Perlas, Aljófar.

\title{
Silverwork, pearls and businesses in the first half of the 16th century. Alonso de Oviedo and his central role in American and commercial Seville.
}

\begin{abstract}
With this work, we will approach the complex and dynamic historical context of the first half of 16th-century Seville, when commercial and financial activity acquired dimensions never seen before in Europe thanks to the emerging possibilities of transactions in the New World. The protagonists of this vital impulse, the Spaniards as well as those from other points in the continent, are only partially known. Day after day, new examples of the "man of business with the Indies» appear. Alonso de Oviedo, who is analysed here, helps us to understand in a broader way the temporal, human and economic space indicated. His profile goes beyond the clichés of this typology, as it adds to his dedication to business, an artistic activity very much connected with the economic development mentioned, such as the art of silverwork, also explored in these lines. The relationship with the businesses of pearls and seed pearls fits within one of the chapters of most interest in the European
\end{abstract}


society of the time, associated with luxury and the mystery of faraway lands and seas. The starting point of this research is a large number of unknown documents from the Archivo General de Indias (General Archive of the Indies) and Archivo Histórico Provincial (Provincial Historical Archive), both from Seville.

Key words: Alonso de Oviedo, Seville, Cubagua, silverwork, pearls, seed pearls.

\section{Argenterie, perles et commerce dans la première moitié du XVI ${ }^{\mathrm{e}}$ siècle. Alonso de Oviedo et son rôle central dans la Séville américaine et mercantile.}

\section{Résumé}

Ce travail propose une approche au complexe et dynamique contexte historique de la Séville de la première moitié du XVI ${ }^{\mathrm{e}}$ siècle, lorsque l'activité commerciale et financière acquièrent quotas inouies, grâce aux possibilités de transactions ouvertes par le Nouveau Monde. Les protagonistes d'un tel élan vital, des espagnols et des gens d'ailleurs, s'avèrent peu connus. Tous les jours surgissent des exemples du prototype de l' "homme d'affaires avec les Indes». Alonso de Oviedo, analysé ici, nous aide à mieux comprendre l'espace temporal, humain et économique en question. Son profil dépasse les traits communs de cette typologie, car il ajoute à son activité mercantile une activité artistique liée au développement économique: l'argenterie. Le rapport avec le marché de perles répond à un engouement propre à l'Europe de cette époque, un marché associé au luxe et au mystère des mers et des terres lointaines. Cette recherche se sert des documents inédits conservés dans l'Archivo General de Indias et l' Archivo Histórico Provincial, à Séville.

Mots-clés: Alonso de Oviedo, Séville, Cubagua, argenterie, perles. 


\section{Introducción}

Alonso de Oviedo, al menos en el campo artístico, sigue resultando del todo desconocido. Igual ocurre para otros integrantes del gremio de la platería de la primera mitad del quinientos, a los que apenas se ha prestado atención, salvo si ejercían actividad para una institución de primer orden como la Catedral hispalense, o se han documentado en relación con alguna obra todavía conservada ${ }^{2}$. Llama la atención su olvido, si reparamos en la multitud de nombres vinculados a la platería, que han logrado recuperar los más recientes estudios centrados en el llamado 'siglo de oro sevillano's. Hasta ahora, únicamente ha sido citado de pasada, por Enrique Otte, en relación con la actividad mercantil ${ }^{4}$, buena prueba de su preferente implicación en el mundo de la moderna economía que, entonces, tenía a Sevilla y a la Carrera de Indias como canales privilegiados de su puesta en escena.

La documentación inédita o poco explorada, rica en matices, del Archivo General de Indias (Sevilla) la entrecruzamos con la que proporcionan las notarías sevillanas del siglo XVI, vital

2 Las primeras noticias, como de costumbre, se las debemos a Gestoso: José Gestoso y Pérez, Ensayo de un diccionario de los artífices que florecieron en Sevilla, vol. II (Sevilla: La Andalucía Moderna, 1900), 273.

3 María del Carmen Heredia Moreno, "Apuntes sobre el tráfico artístico con América en el siglo XVI. Artistas, artesanos y mercaderes en la Carrera de Indias,» en El arte español fuera de España, coord. Miguel Cabañas (Madrid: CSIC, 2003), 193-206, de la cita, 195; 197-198 y 205-206. María Jesús Sanz, «Plateros sevillanos y estantes en Sevilla que comerciaban con América entre 1525 y 1550,» en Estudios de platería San Eloy, ed. Jesús Rivas Carmona (Murcia: Universidad, 2015), 555-570. Antonio J. Santos Márquez, «Nuevas pruebas documentales de la implicación del arte de la platería hispalense en el tráfico comercial y artístico con las Indias (1530-1630),» en El tesoro del lugar florido. Estudios sobre la plata iberoamericana. Siglos XVIXIX, coords. Juan Haroldo Roda y otros (México: INAH; León: Universidad, 2017), 25-38, de la cita, 32-35. Francisco Javier Herrera García, «Platería y comercio en Sevilla durante la primera mitad del XVI: Juan Ruiz "el Vandalino" y su vertiente mercantil,» en La plata en Iberomérica. De los orígenes al siglo XIX, coord. Jesús Paniagua (en prensa).

4 Enrique Otte, «El proceso del rastro de perlas de Luis de Lampiñán,» Boletín de la Academia Nacional de la Historia, no 187 (1964): 387-388 y 395. Enrique Otte, Las perlas del Caribe: Nueva Cádiz de Cubagua (Caracas: Fundación John Boulton, 1977), 66, 69, 71, 403, 423, 539-540. Enrique Otte, Sevilla y sus mercaderes a fines de la Edad Media (Sevilla: Universidad y Fundación El Monte, 1996), 163, 202. Enrique Otte, Sevilla, siglo XVI: materiales para la historia económica (Sevilla: Centro de Estudios Andaluces, 2008), 193, 200, edición en PDF. 
para reconstruir su andadura y profundizar en el conocimiento del comercio transatlántico de ese siglo, documentación hoy resguardada en el Archivo Histórico Provincial de Sevilla, sección Notarías de Sevilla, cotejada además con bibliografía específica sobre el comercio y la platería de esta ciudad, y su relación con América en el XVI.

La intensa vinculación con el tráfico mercantil, operaciones de representación, préstamos, los vínculos con otros plateros, viajes e intereses en América, así como predilección por la compraventa de perlas, le convierten en un modélico hombre de la época, abierto a las grandes oportunidades del comercio indiano, sin olvidar el oficio de platero, al que se dedica en ocasiones. Alonso de Oviedo fue hombre inquieto, dispuesto a la aventura y empresas inciertas, con dotes artísticas pero orientado a las operaciones mercantiles arriesgadas, por las altas deudas que comportaban. En definitiva, un buen prototipo de hombre de negocios del quinientos, dotado de ese carácter polivalente del comerciante hispano del momento ${ }^{5}$, incluso traspasando las fronteras de varias ocupaciones: productor, intermediario, artista. Las ansias de riquezas y el poder que de ellas derivaba, parece ser el norte de sus actividades.

\section{Aproximación a su biografía}

Respecto a su andadura vital es muy poco lo que conocemos con claridad, pero algunas pistas documentales nos permiten adivinar que llegó a Sevilla con intenciones de prosperar, en primer lugar ejerciendo su oficio y, pronto, adentrándose en las nuevas posibilidades de prosperidad que ofrecía la actividad mercantil y económica en general, que con ímpetu se desarrollaba en la ciudad en las primera décadas del XVI, descubriendo al instante la mecánica y riesgos del comercio con América, en el que apostó con decisión. Todo ello lo evidencia la

\footnotetext{
5 La polivalencia, diversidad de tratos y operaciones, variedad de segmentos mercantiles, distintos volúmenes de mercancías, la constante búsqueda de la ocasión, vienen a definir el perfil de los mercaderes del XVI, según ha hecho ver Antonio García-Baquero González, La Carrera de Indias: suma de la contratación y océano de negocios (Sevilla: Algaida y Expo 92, 1992), 291.
} 
abundante documentación existente en las notarías sevillanas y Archivo General de Indias. Desconocemos su lugar de nacimiento, que pudiera haber acontecido en Asturias, si nos guiamos por su apellido, quizás alusivo a la ciudad donde vino al mundo, como era frecuente en tiempos medievales y en la edad moderna. Seguramente arribaría a Sevilla procedente de Toledo, donde habitaban sus padres y hermanos. Debió llegar a Andalucía hacia 1515-1520, cuando algunos testigos, en un pleito de 1531-1534, declaran haberle conocido por primera $v^{2} z^{6}$. Con exactitud sabemos que su padre, Juan de Oviedo, de oficio también platero, procedía de Toledo y se encontraba en Sevilla en 1524, al igual que sus hermanos Pedro, clérigo presbítero, y Juan, asimismo platero. Es posible que fuera Alonso quien atrajera a la familia hasta Sevilla. En marzo de 1526 se declaran todos vecinos de Toledo, cuando el progenitor arrienda en esa ciudad a Diego de Mora y Lorenzo Suárez, calceteros, vecinos de Toledo, una casa-tienda con soberado y azotea, por tiempo de 4 años, y precio de 9.500 maravedís al año y 4 «pares de gallinas buenas y vivas». Debe tratarse de la casa donde Juan y quizás también Alonso, vivieron y tendrían el taller en la ciudad imperial, a la que no pensarían volver, pues el mismo día deciden vender la mitad de las citadas casas a maestre Gil Mallero, presente entonces en Sevilla, por 25 ducados de oro $^{7}$. Es una prueba concluyente del definitivo asentamiento en Sevilla del clan.

Estuvo casado al menos en una ocasión, así lo declaró en 1529 cuando emprendió el único viaje a territorio americano que hemos podido documentar, a Cubagua y Santo Domingo, en calidad de factor de Juan Antonio Picolomini y Scipione Pechi, mercaderes sieneses, y que transcurrió entre

\footnotetext{
6 En las testificaciones que tuvieron lugar en 1531 sobre el pleito por la devolución de 14 onzas y una ochava de perlas, que enfrentó a Juan Antonio Picolomini, mercader sienés, con Alonso de Oviedo, algunos testigos, como el escribano Diego Fernández, declara haber conocido a Oviedo, desde hacía unos 14 años. Otros declaran conocerle desde 10 años, como Cristóbal de Barahona y el platero Juan Ruiz, en 1532 dice conocerle desde hacía 12 años. "Alonso de Oviedo contra Juan Antonio Picolomini», Sevilla, 1531-1534, Archivo General de Indias (AGI), Sevilla-España. Sección Justicia [J], 707, N. 1, pieza 4, s/f.

7 Archivo Histórico Provincial de Sevilla (AHPS), Sevilla-España. Sección Notarías de Sevilla (NS), leg., 3264, of. 5, ff. 64v; 66v; 67r.; 69v. 1526-III-22.
} 
la segunda quincena de abril de 1529 y el 24 de diciembre de 1530, día en que desembarcó en Sevilla de regreso. Desconocemos el nombre de su esposa en esos momentos, pero ha trascendido más adelante, en 1537, que su cónyuge era Isabel de Castañeda ${ }^{8}$, no sabemos si pudiera tratarse de la misma u otra mujer. No está de más señalar, siguiendo a Juan Gil, que el apellido Castañeda emparentó con conversos en el siglo XVI, así tenemos a una Isabel de Castañeda, mujer de Alonso de Oviedo, que otorga testamento en 1578, ya viuda, sin descendencia ${ }^{9}$, que quizás fuera la misma, aún con vida cuarenta y siete años después de la anterior fecha. Nada podemos aventurar sobre posibles hijos.

Habitó en Sevilla en la collación de la Magdalena y en el entorno catedralicio, o collación de Santa María, centro del arte de la platería y las operaciones mercantiles y financieras, donde tuvo tienda, en la alcaicería de los plateros, y abundante trato con los colegas de oficio, como el principal de los plateros sevillanos de la primera mitad de siglo, Juan Ruiz "el Vandalino», junto a sus hermanos Bartolomé y Francisco, su cuñado Cristóbal Tercero, y otros plateros como Diego de Vozmediano, Cristóbal de Medina, vecino de Lisboa, Diego de Nava y Cristóbal de Quintanilla, afincados en Santo Domingo, Francisco de Castro, Fernando de Antezana, Pedro de Villanueva, Francisco Morcillo, Juan Sánchez, Juan Marroquí, Juan de Palma, Alonso Fernández y Alonso Bernal. También es nutrido el grupo de mercaderes, hombres de negocios y maestros de distintas artes con las que tuvo tratos, en primer lugar los citados mercaderes sieneses Juan Antonio Picolomini y Scipion Pechi, Diego Sánchez de Toledo, Alfonso de la Serna, Francisco de París, Diego Pachón, el polifacético jurado Francisco de la Corona, Domingo de Zornoza, Alonso de Solana, Andrés de Osarga, Segismundo Benasay, Cebrián de Caritate, Cristóbal Gutiérrez de Sanvítores, Leonardo y Gregorio Cataño, Juan de Espinosa, Rodrigo de Hermosilla,

8 Consta que en 1537 habitaba una casa en compañía de su esposa Isabel de Castañeda, situada frente a las gradas de la catedral y la casa era propiedad del cabildo eclesiástico. Gestoso, Ensayo, II, 273.

9 Juan Gil, Los conversos y la Inquisición sevillana, Vol. III (Sevilla: Universidad de Sevilla y Fundación El Monte, 2001), 468. 
sastre, el banquero Diego de la Haya, el arzobispo Alonso Manrique de Lara, etc.

Interesa igualmente señalar, en relación con sus frecuentes contactos con banqueros, que disponía tiendas de su propiedad en la calle de las Gradas, arrendadas entre 1537 y 1543 al banquero público Juan Íñiguez, limítrofe a la tienda que utilizaba el célebre banquero procedente de Medina de Rioseco, Pedro de Espinosa. También limitaba la citada tienda con las casas de morada de Oviedo, propiedad de la catedral ${ }^{10}$.

Su arrojó a la hora de contraer deudas y la imposibilidad de satisfacerlas, le llevaron a la cárcel, al menos en una ocasión entre diciembre de 1530, cuando regresó preso de la Española, y finales de febrero de 1531. Entre los productos con los que traficó destacan las perlas y el aljófar, fuente de algunos quebraderos de cabeza, como el antes aludido pleito con Picolomini. Tampoco podemos precisar la fecha de su fallecimiento, si bien es seguro que vivía aún en 1543, cuando declara disfrutar de una tabla de carnicería en la collación del Salvador, propiedad de la Cartuja de Santa María de las Cuevas ${ }^{11}$.

\section{Los indicios de actividad laboral como platero}

Entre los primeros datos que nos informan de su dedicación al oficio para el que se formó, destaca precisamente un contrato de aprendizaje fechado en 1525. En enero de ese año Isabel González, viuda de Martín Muñoz, vecina de Guadalcanal, pone a servir por aprendiz a Francisco, su sobrino, hijo de Lope Fernández y de Leonor Gutiérrez, difuntos, de 12 años de edad, con Alonso de Oviedo, vecino de la collación de Santa María, desde el primer día de enero y durante 6 años, al cabo de los cuales le abonará 5.000 maravedís, debiendo enseñarle el oficio de platero cumplidamente ${ }^{12}$. 
No parece que funcionara la compañía que en marzo de 1524 había convenido con el platero de la catedral Diego de Vozmediano, "para labores de su oficio», pues el 18 de mayo de 1525 Alonso y su padre Juan, según dijimos también platero y partícipe de esta unión temporal, se obligaban a devolver la cantidad que había invertido en la misma Vozmediano, un total de 35.945 maravedís, a razón de 3.000 maravedís mensuales ${ }^{13}$. Desconocemos más detalles, pero, los datos citados, nos avisan de una evidente práctica del arte de la platería, en el que ejercía igualmente su padre, y el posible intento de vincularse a través de Vozmediano, platero catedralicio, con los abundantes encargos de la catedral ${ }^{14}$. Pero la empresa no debió funcionar por desacuerdos entre las partes o motivos que desconocemos.

No fue la única compañía que pretendió con otros profesionales del gremio de la plata, aparte de las dedicadas a fines comerciales, que luego veremos. Es posible que el intento no llevado a cabo de formalizar una de estas uniones temporales, quizás de carácter laboral, con el platero Juan Ruiz "el Vandalino», en agosto de 1527, tuviera propósitos profesionales, sin embargo, las hojas del legajo notarial donde iba a escriturarse quedaron en blanco, si bien constan las firmas de ambos, indicadoras de su inicial intención y la escueta mención, junto a las anteriores, "Compañía que fizimos por un año» ${ }^{15}$. Quizás se arrepintieran a última hora o dieran por suficiente un acuerdo verbal. No sería extraño que emprendieran algunas obras compartiendo el trabajo y la inversión, si tenemos en cuenta la intensa actividad que registra el taller de Ruiz, que llevaría a este último en diversas ocasiones a establecer acuerdos de colaboración con otros plateros, como fue el caso de Francisco de Castro ${ }^{16}$.

13 AHPS, NS, leg. 3257, of. 5, f. 273v. 1524-III-12 y leg. 3260, of. 5, f. 255r. 1525V-18.

14 Sobre Diego de Vozmediano véase Jesús M. Palomero Páramo, «La platería en la Catedral de Sevilla," en La Catedral de Sevilla, coord. Diego Angulo (Sevilla: Guadalquivir, 1991), 575-645, de la cita, 594 y 631-632. Heredia, «Apuntes sobre el tráfico», 202. Sanz, «Plateros de la Catedral de Sevilla en la primera mitad del siglo XVI y sus relaciones con América", 734-735.

15 AHPS, NS, leg. 3270, of. 5, f. 162r.

16 Herrera, «Platería y comercio», (en prensa). 
En ocasiones parece que el establecimiento de compañías o acuerdos de cooperación con otros plateros, únicamente intentaban aliviar la carga de trabajo o traspasar encargos y compromisos, quizás con vistas a una mayor dedicación al tráfico mercantil. Así parece que hizo con el platero Pedro de Villanueva, quien a finales de septiembre de 1532 otorgaba poder a Bartolomé Ruiz, también platero y hermano del citado "Vandalino», para que en su nombre cobrara a Oviedo "[...] todos los mrvs. e otras cosas q. me deba asy de obra q. le aya fho. del dho. ofiçio de platero, como de qlesqr. cuentas e otras cosas [...]» ${ }^{17}$. Hacia 1533 tuvo también estrechas relaciones económicas con el platero Cristóbal Tercero, cuñado de Juan Ruiz «el Vandalino» y puede que tuvieran relación con asuntos de la profesión pues, declara Tercero, que Ruiz había abonado en su nombre a Alonso de Oviedo cierta deuda que con él había contraído "[...]de çierta plata e para comprar çiertas mercaderías e cosas q. yo llevo a la Nueva España a donde agora voy[...]» $»^{18}$.

Las compras de oro y plata pueden posicionarle entre los plateros que ejercían la profesión de compradores de metales para su posterior acuñación en la Casa de la Moneda o incluso se adentraban en el mundo del cambio y las finanzas, tal como ha estudiado Donoso Anés ${ }^{19}$. Pero es lógico pensar también que algunas de estas operaciones, estarían relacionadas con la adquisición de materia prima, para su posterior aplicación a las tareas del oficio. Entre los ejemplos que nos avisan de ese tipo de compraventa de metales, tenemos dos noticias de 1535, una referida a la obligación de pagar la plata que Juan Borrallo le había traído del Perú, junto al batihoja Alonso Fernández, y cuyo importe ascendía a la crecida suma de 325.998 maravedís ${ }^{20}$. Ese mismo año había adquirido oro al

17 AHPS, NS, leg. 3294, of. 5, f. roto. 1532-IX-30.

18 AHPS, NS, leg. 3299, of. 5, s/f. 1533-VIII-23. Citado en Herrera, «Platería y comercio», (en prensa).

19 Rafael Donoso Anés, «Mercado y mercaderes de oro y plata de Sevilla en la segunda mitad del siglo XVI,» en Dinero, moneda y crédito en la monarquía hispánica, coord. Antonio Miguel Bernal (Madrid: Marcial Pons, 2000), 213-239.

20 AHPS, NS, leg. 3309, of. 5, s/f. 1535-IV-3. 
escribano de su majestad Fernando de Medina, por valor de 50.000 maravedís $^{21}$.

Según hemos expuesto en otra ocasión, Alonso de Oviedo figuró entre el grupo de artistas y comerciantes, que en enero de 1536 otorgaron fianza a Juan Ruiz «el Vandalino», cuando este último se compromete a ejecutar la magna custodia, desaparecida en 1936, de la iglesia catedral de Jaén. Este compromiso alejó de Sevilla a Ruiz, residiendo en Jaén durante unos cuatro o cinco años para su confección. Es posible que Oviedo asumiera, al menos en parte, algún otro encargo pendiente en el taller sevillano de Juan Ruiz, como pudo ser la custodia de la catedral de Santo Domingo (República Dominicana), afortunadamente conservada y cuyas marcas no dejan lugar a dudas de su confección en Sevilla, al figurar la torre o "Giralda", con los caracteres en parte frustros de «Sevilla». Pero especialmente reparamos en otra marca, que se repite en esa importante pieza al menos dos veces, un recuadro de ángulos ochavados que contiene una "A» dentro de una "O $\|^{22}$ que, pudieran corresponderse con las iniciales del nombre y apellido de Alonso de Oviedo. Es posible que actuara como contraste, pero no hemos de descartar que compartiera la ejecución de esta custodia con Ruiz, ocupado de forma permanente en Jaén hasta 1540 y, si tenemos en cuenta que parece fue estrenada en la capital de La Española en el corpus de 1542, escaso sería el tiempo de su manufactura, a no ser de la colaboración con Juan Ruiz de otros maestros, quizás Alonso de Oviedo ${ }^{23}$.

\footnotetext{
21 AHPS, NS, leg. 3313, of. 5, s/f. 1535-XII-14.

22 Restauración de una custodia procesional procedente de la Catedral de Santo Domingo (República Dominicana). 1992. Instituto de Patrimonio Cultural de España. Archivo. Expediente y fotografías, signatura BM 194/16. Agradezco a la restauradora Dña. Paz Navarro Mazón, que me pusiera al tanto de este documento y la información sobre la restauración de la custodia.

23 Herrera, "Platería y comercio», (en prensa). Sobre la custodia de la Catedral Primada de Santo Domingo, véase Diego Angulo, El Gótico y el Renacimiento en las Antillas (Sevilla: EEHA, 1947), 49-50. Erwin Walter Palm, «The treasure of the Cathedral of Santo Domingo,» The Art Quarterly, n 13 (1950): 120-122. José Manuel Cruz Valdovinos, Cinco siglos de platería sevillana (Sevilla: Ayuntamiento, 1992), 2835. José Manuel Cruz Valdovinos y Andrés Escalera Ureña, La platería de la catedral de Santo Domingo, primada de América (Madrid: Tabapress, 1993), 67-76. María Jesús Sanz Serrano, La custodia procesional: Enrique de Arfe y su escuela (Córdoba: Cajasur, 2000), 80-81 y 114-119.
} 
Tales suposiciones resultan difíciles de demostrar, de momento, pero tienen visos de probabilidad amén de las estrechas relaciones en el plano mercantil que sostuvieron Juan Ruiz y Alonso de Oviedo. Que interviniera en el peritaje de ciertas obras confeccionadas por otros plateros, cuyo valor exacto debía comprobarse, no indica otra cosa que su familiaridad con los productos argénteos, sus calidades y la propia habilidad en la confección de los mismos. En calidad de perito lo tenemos en 1537, inspeccionando el ajuar de plata labrado en Sevilla por el platero Francisco Morcillo, para la iglesia franciscana de Panamá, encargado por Pedro Navarro, un indiano enriquecido y el prior del convento, compuesto por un cáliz y patena que pesan 3 marcos, un incensario de 2 marcos, 4 onzas, una ochava y tres tomines, una custodia de 4 marcos y 6 onzas y una cruz de 9 marcos, 3 onzas y 6 ochavas de plata, todo lo cual fue sometido a la inspección de su valor y calidad, antes de partir a Centroamérica ${ }^{24}$, por Alonso de Oviedo y el también platero Andrés Sánchez.

Pero la prueba más certera de su actividad como maestro del arte de la platería no puede ser otra que la ejecución de obras, de las que sólo tenemos documentado un ejemplo. Se trata del compromiso para realizar una custodia, tipo ostensorio, para el convento dominico de San Pablo de Sevilla. El 30 de julio de 1532 declaraba recibir de mano de Diego de Luque, sacristán del monasterio, 10 marcos, una onza y un real de plata de marcar, valorado cada marco en 1.210 maravedís, para con ellos realizar una custodia cuyo peso estaría comprendido entre 10 y 11 marcos (entre 2,30 y 2,53 kilogramos), debiendo entregarla en el transcurso del siguiente mes de noviembre. Estipulaban las condiciones, entre otras cosas, que si fuera necesaria más plata se le abonaría a Oviedo y este cobraría por su trabajo lo que determinaran dos oficiales del gremio de plateros, uno dispuesto por el convento y otro por el artífice. Los dominicos podrían elegir otro artífice si finalmente no fuera realizada la obra, obligándose Alonso a la devolución de 
la materia prima ${ }^{25}$. Esta pieza no se conserva, ni volvemos a tener más noticias de ella.

Con los datos expuestos queda demostrada la actividad como platero de Oviedo, labor que no debió ser continua, sino complementada y alternada con sus ocupaciones mercantiles, quizás las más importantes en su trayectoria vital.

\section{Segmentos de su ocupación mercantil e inversora}

Participó activamente en el variopinto y desbordante comercio sevillano del XVI, cuyo principal objetivo y miras estaban puestas en las Indias, haciendo uso de los habituales instrumentos de pago y financiación. Responde, tal como indicamos, a esa figura de mercader multifacético, escasamente especializado, que caracterizó a la mayoría de los operadores en esa red mundializada de intercambios ${ }^{26}$.

Si nos fijamos en las habituales compañías comerciales, en 1527 podemos situar el mutuo acuerdo entre Alonso de Oviedo y el vecino de Toledo Alonso de la Fuente, en virtud del cual el segundo viajaría a Santo Domingo, estableciendo allí durante cuatro años una tienda para la venta de ropa y otras mercaderías que regularmente remitiría Oviedo desde Sevilla. El primer viaje lo hace en compañía de cuatro esclavos y una esclava negra, además del criado del platero, Juan de Oviedo, quizás hermano menor, del mismo oficio. La compañía se constituyó sobre un fondo de 800 ducados de oro dispuestos por ambos a partes iguales. Alonso de la Fuente se obliga a gestionar la tienda y enviar el oro, plata y otras mercancías como azúcar a Oviedo en Sevilla. Además, contratará un mozo que se encargue de la tienda, cuyo salario, así como la renta de la tienda y casa donde habitaría el socio factor, correría a cargo del platero ${ }^{27}$. Según observamos, se trata de la típica compañía en la que se comparten gastos y uno de los socios se desplaza al otro lado del océano para beneficiar mercancías 
y obtener ganancias en metálico o en especie, que remite al socio estante en Sevilla, herencia según sabemos, de las "commenda" medievales, muy utilizadas por los comerciantes italianos y de otros puntos de Europa durante la Edad Media, ahora subsistentes en el nuevo tráfico comercial entre España y América ${ }^{28}$.

Centrándonos en bienes concretos, en ocasiones adquirió productos agrarios de primera necesidad como el trigo, seguramente con la intención de transformarlo en harina para su exportación a Indias o venderlo a los fabricantes de bizcocho que suministraban el básico producto a las naves de la Carrera. Debieron tener finalidad exportadora las 150 fanegas que ordena comprar a su criado Bartolomé Martín fuera de las 15 leguas de la jurisdicción del cabildo sevillano ${ }^{29}$, tal como estableció este organismo poco antes de 1525 para el trigo destinado a América, con el propósito de garantizar el abastecimiento de la ciudad y su entorno, a la vez que posibilitar la exportación ${ }^{30}$. También localizamos la compra de una partida del producto estrella del agro sevillano, el aceite de oliva. En octubre de 1528 se obligaba a pagar en ocho meses al mercader Alfonso de la Serna, 27.167 maravedís, por cierto aceite que le vendió ${ }^{31}$. Es posible que este aceite estuviera ya previsto para su traslado a Cubagua y Santo Domingo, en el viaje que emprende a finales de abril del siguiente año.

Dentro del variado repertorio textil, parece que se adentró en la compra y exportación tanto de ropa confeccionada como de tejidos de cierta calidad, así ocurrió con la seda y los terciopelos que podemos situar entre los textiles más valorados de los exportados al continente americano, y de los que Sevilla era productora y receptora de otros centros peninsulares como Murcia o Granada ${ }^{32}$. En 1527 adquirió Alonso de Oviedo una

28 García-Baquero, La Carrera de Indias, 240-243.

29 AHPS, NS, leg. 3269, of. 5, f. 352r. 1527-VII-10.

30 Otte, Sevilla, siglo XVI, 151.

31 AHPS, NS, leg. 3275 , of. 5, f. 283r. 1528-X-15.

32 Antonio Miguel Bernal, Antonio García-Baquero y Antonio Collantes de Terán, Sevilla, de los gremios a la industrialización (Sevilla: Ayuntamiento, 2008), 107-115. Otte, Sevilla, siglo XVI, 105-106 y 211-213. 
partida importante de seda tejida, al mercader Martín de Baena, valorada en 50.751 maravedís, que habría de abonar en 6 meses. Uno de los máximos especialistas en seda y terciopelo de los años veinte y treinta del siglo en Sevilla fue el mercader burgalés y jurado del concejo de Sevilla, Francisco de la Corona ${ }^{33}$, a quien Oviedo se obligaba a saldar en junio de 1528 , en siete meses, la ingente suma de 114.356 maravedís, por ciertas «sedas-terciopelos» que le había vendido ${ }^{34}$.

La mayoría de las deudas que contrae Oviedo por mercaderías no citan los productos integrantes de las mismas. En ocasiones se alude a productos como hilo de lencero, del que había enviado 250 libras en 1532 por Gaspar de Montalván a Rodrigo de León y Antxon de Jaén, estantes en Nueva Cádiz en la isla de Cubagua ${ }^{35}$. El lienzo de Ruan fue una de sus especialidades, si nos atenemos a los distintos documentos que aluden a la compra de diversas cantidades de este género, como hace en 1537 al mercader Jerónimo Ferrera, por valor de 25.826 maravedís ${ }^{36}$. En 1539 adquirió un fardel de «ruanes» por 27.882 maravedís a Alonso de $\mathrm{Haro}^{37}$ y, en 1543, llegó a pagar la suma de 173.236 maravedís a Juan de Castro y herederos por cuatro cofres de lienzo de Ruan ${ }^{38}$.

Fue diversa la procedencia de los mercaderes con los que Oviedo realiza tratos. Ya citamos a los sieneses y podemos agregar a genoveses como Gregorio Carta, Leonardo Cataño de Angelo, y su hermano Gregorio; portugueses como Francisco Gil o burgaleses como Francisco Gutiérrez al que en 1532 declara deber 45.450 maravedís por mercaderías, comprometiéndose a abonar la deuda en dos años con el

33 Sobre la ocupación por mercaderes burgaleses de cargos en el concejo de la ciudad de Sevilla véase Natalia Palenzuela Domínguez, «Los mercaderes y hombres de negocios burgaleses en Sevilla en tiempos de Isabel la Católica,» en Comercio y hombres de negocios en Castilla y Europa en tiempos de Isabel la Católica, eds. Hilario Casado y Antonio García-Baquero (Madrid: SECC, 2007), 350-352.

34 AGI, J, 707, N. 1, pieza 3, s/f. 1528-VI-18.

35 AHPS, NS, leg. 3292, of. 5, fol. 452r. 1532-VI-8. El envío a Cubagua incluía tres resmas de papel.

36 AHPS, NS, leg. 3323, of. 5, f. 229r. 1537-VIII-3.

37 Otte, Sevilla, siglo XVI, 193. 1539-V-30.

38 Otte, Sevilla, siglo XVI, 200. 1542-V-25. 
respaldo como fiadores de los plateros Francisco de Castro y Juan Ruiz «el Vandalino» ${ }^{39}$. Otro de los burgaleses, ya indicado, con los que tuvo trato fue el jurado Francisco de la Corona y en tercer lugar Cristóbal Gutiérrez de Sanvítores, quien le provee de gran parte de las mercancías transportadas a Cubagua y Santo Domingo en 1529, por valor de 150 ducados de oro (56.250 maravedís) y que continuaban pendientes de cobro el año siguiente, pese al compromiso del sienés Scipion Pechi de abonarlos ${ }^{40}$.

Los productos americanos que interesan a Alonso de Oviedo son los habituales del momento, en primer lugar, oro, plata y perlas, según veremos, pero también los cueros, cañafístola, sustancias tintóreas y, de forma particular, el azúcar antillano. En 1527 tenemos el ejemplo de una de sus mayores inversiones, en relación con este edulcorante, al proceder en compañía del sastre Rodrigo de Hermosilla, a la adquisición de "[...] un engenio poderoso de agua de faser Açucar qesta en termino de la villa del Bonao de la Ysla española de las yndias[...]», con todo lo que le pertenece ${ }^{41}$. El vendedor, presente en Sevilla entonces, fue Miguel de Lumbrales. Las otras tres cuartas partes son propiedad de Fernando del Castillo y de Pedro de Barruelo, escribano de la ciudad de Santo Domingo. El precio que se comprometen a abonar Oviedo y Hermosilla ascendía a 400.000 maravedís que debería ser satisfecho en un año y un mes de plazo.

La compra del ingenio llegó a materializarse pues, el 31 de mayo de 1527, Alonso de Oviedo y Rodrigo de Hermosilla, envían poder a Diego de Nava y Cristóbal de Quintanilla, plateros vecinos de la ciudad de Santo Domingo, para que en su nombre cobren cualquier cuantía de mercaderías, dinero,

39 AHPS, NS, leg. 3295, of. 5, f. 986r. 1532-XII-17; f. 1037r. 1532-XII-23; leg. 3298, of. 5 , f. roto. $1533-\mathrm{V}-29$.

40 AHPS, NS, leg. 3276, of. 5, fol. 594r. y 461r. leg. 3283, of. 5, fol. 197r. 1530-VI-15. 41 AHPS, NS, leg. 3268, of. 5, f. 261r. 1527-IV-8. Entre los compradores y el vendedor existían deudas anteriores, como los 44.620 maravedís, que Lumbrales debe a Oviedo, pues en su lugar pagó unos lienzos que le había vendido Domingo de Zornoza, y ahora compensan en el pago del ingenio. AHPS, NS, leg. 3268, of. 5, f. 412v. 1527-V-11. F. $399 v .1527-\mathrm{V}-29$. 
así en La Española como en otras partes de Indias, llevando cuenta y razón y añadiendo,

[...] Otros y le damos mas poder comp ${ }^{\circ}$. pa. q. en nro. nombre e pa. nos puedan entrar e tomar la tenencia e posesión de qualqer. engenio de moler e fazer açucar o de qualquer. pte. dellos q. nosotros thenos. e nos pteneçe. asy en termyno de la villa del Bonao de la dha. Isla Española como en otras ptes. qualesqer. de las dhas. Yndias[... $]^{42}$.

El negocio del azúcar llegado de Santo Domingo, fue por esos años un segmento importante de las actividades mercantiles de Oviedo, no sabemos si procedente de su ingenio de la localidad de Bonao o de otros de los abundantes centros productores en la isla antillana. No faltaron los infortunios, como la pérdida de una carga del preciado producto, debido al naufragio de la nao que la transportaba, nombrada La Trinidad. En 1534 Oviedo inicia un litigio que le enfrenta al maestre de la citada nao, Diego Sánchez Colchero, a quien reclama el importe de ocho cuartas de azúcar mascabado y espumas, registradas en Santo Domingo a nombre de Juan de Salamanca Varela, vecino de Sevilla, quien después de venderlas debía entregar su importe a Alonso de Oviedo ${ }^{43}$. El cargamento fue consignado en el puerto dominicano entre el 1 y 5 de diciembre de 1528 por Miguel de Lumbrales. Semanas después de zarpar, la embarcación fue presa de una violenta tormenta que casi la destruye; sin embargo, a duras penas logró arribar al puerto de Santa Cruz en la isla de Flores (Azores), donde se hundió perdiéndose gran parte de la cargazón. Oviedo alega que su azúcar estaba entre lo que pudo salvarse, pero el maestre se apropió de ella. Uno de los testigos, el pasajero Pedro de Villalobos, alegó que el cargamento del platero venía en el fondo de la embarcación, bajo la ropa, y no

\footnotetext{
42 AHPS, NS, leg. 3269, of. 5, f. 57r. 1527-V-31. En 1530 falleció Miguel de Lumbrales, pues ese año Domingo de Zornoza otorga poder a Alonso de Oviedo, para que cobre de los bienes que quedaron del anterior, la cantidad de 44.620 maravedís, aún pendientes por la venta que le hizo de lienzos. AHPS, NS, leg.3285, of. 5, f. 470v. 1530-X-19.

$43 \mathrm{El}$ proceso se inicia el 9 de enero de 1534, reclamando Oviedo al citado maestre las 8 cuartas de azúcar mascabado y espumas, valoradas cada cuarta en 30 ducados, en total 240 ducados (90.000 maravedís). «Alonso de Oviedo contra Diego Sánchez Colchero,» Sevilla, 1534-1536. AGI, J, 718, N 10, s/f.
} 
pudo rescatarse ${ }^{44}$. Desconocemos el desenlace del pleito que, mucho nos tememos, no resultó favorable a los intereses de nuestro protagonista.

\section{Perlas y aljófar como ambición y fuente de problemas}

Desde el tercer viaje de Colón, las perlas se revelaron como una de las más apreciadas riquezas que podía deparar América. Las perlas del Nuevo Mundo, producidas fundamentalmente en el Caribe, llegaron en fechas tempranas del XVI a transformar el mercado tradicional del producto marino y jugarían un papel fundamental en los nuevos derroteros del comercio a escala planetaria ${ }^{45}$. Desde el Caribe, durante el siglo XVI, fueron enviadas perlas por millones hacia Europa, convirtiéndose Sevilla en uno de los puntos fundamentales de distribución de las mismas, tanto en España como en el resto del continente ${ }^{46}$. Las perlas del Caribe ejemplifican por encima de otros productos, la mundialización de la economía y las relaciones humanas de la época; obtenidas en el Caribe por los naturales y también hombres esclavos procedentes de África, viajaron de mano de mercaderes, funcionarios y particulares hasta la Península Ibérica, desde donde llegan posteriormente a los rincones más lejanos de Europa, atendiendo a finalidades suntuarias, pero también a la necesaria liquidez de un sinfín de operaciones mercantiles y financieras ${ }^{47}$. Las perlas, por su variedad, tamaño y calidades presentan un valor oscilante, que hizo posible su adquisición por casi todos los estamentos sociales y presentaron múltiples quebraderos de cabeza a las autoridades y mercaderes del XVI, pues no existía una norma regulada para su universal clasificación. Aquí radica uno de los principales problemas para hacernos hoy una idea, de la verdadera calidad y apariencia de las perlas aludidas en la documentación, pues los términos empleados difieren según

44 Según declaración de Diego Sánchez Colchero, basándose en el inventario que estaba en poder de la Casa de la Contratación, 1424 cueros, 51 cajas y media de azúcar, 594 pellejas de carnero, 10 pipas, dos cuartos y una caja de cañafístola, 8 costales de lana, una pipa y cuarta de sebo. AGI, J, 718, N 10, s/f.

45 Molly A. Warsh, American Baroque. Pearls and the nature of Empire, 1492-1700

(Chapel Hill: University of North Carolina press, 2018), 12.

46 Otte, Las perlas del Caribe, 75-76.

47 Warsh, American Baroque, 57 y 81. 
el lugar. Una vez clasificadas, para su peso se aplicó el marco, la onza y la ochava, igual que para los metales ${ }^{48}$.

La mejor expresión de lo que significó Sevilla a lo largo del XVI, de forma particular en la primera mitad de siglo, para el comercio de perlas, la tenemos en la amplia y variada documentación notarial, que da cuenta de compraventa de perlas y aljófar. El negocio de este producto interesó de forma particular a Alonso de Oviedo, de manera que podemos intuir su experiencia en la materia. En diferentes ocasiones le hallamos traficando con perlas o aljófar, como en febrero de 1527 cuando se compromete a pagar a los genoveses Angelo y Gregorio Cataño, 62.576 maravedís, en plazo de cuatro meses por "cierto aljófar» que le vendieron ${ }^{49}$. Resulta imposible en estas transacciones conocer algo del tamaño y calidad de las perlas, pues la documentación es parca en cuantificación o clasificación. Un año después, se endeuda por 15.755 maravedís con el mercader Luis García por una cantidad inespecífica de perlas que le vendión ${ }^{50}$. En febrero del mismo año de 1528, era el también genovés Gregorio Carta, quien le proveyó de aljófar, por el que se compromete a abonarle en cuatro meses, 38.964 maravedís ${ }^{51}$. Ese mismo año adquirió aljófar y perlas por importe de 70.475 maravedís a los plateros y mercaderes de oro y plata Juan Marroquí y Juan de Palma, cantidad que adeudaba aún en $1530^{52}$. Todas estas transacciones tienen lugar en los momentos de máxima producción de los ostrales de la isla de Cubagua o Isla de las Perlas, a la que dirigió sus pasos Oviedo en 1529, según veremos. Desconocemos el empleo que daría a las mismas el platero, quizás la fabricación de joyas, aunque más bien hay que pensar, conociendo su deriva mercantil, en la reventa lejos de Sevilla.

48 Otte, Las perlas del Caribe, 36-41.

49 AHPS, NS, leg. 3267, of. 5, f. 338r. 1527-II-9.

50 AHPS, NS, leg. 3272 , of. 5 , f. 178 r. 1528-I-18.

51 AHPS, NS, leg. 3273, of. 5, f. 274r. 1528-III-23.

52 Declaración de las deudas contraídas por Alonso de Oviedo con anterioridad a 1529 y a cuyo pago se comprometen Juan Antonio Picolomini y Scipion Pechi. AGI, J, 707 , N. 1, pieza 4, s/f. 1530-VI-14. 
Las perlas y el comercio llevarían a Oviedo a Cubagua y Santo Domingo. Todo se inicia con la constitución de una compañía mercantil para el transporte de mercancías hasta las citadas islas caribeñas y el rescate de perlas, por los citados sieneses Juan Antonio Picolomini y Scipion Pechi, participando el primero en tres cuartos de la misma y el segundo en un cuarto. Su constitución tuvo lugar el 28 agosto de 1528, para lo que habían adquirido una licencia de navegación directa desde Sevilla a Nueva Cádiz en Cubagua, con la condición de regresar por Santo Domingo y registrar allí las perlas y el resto de la carga. Contaban con una carabela y un galeón, de cuyo aparejo se encarga el platero ${ }^{53}$. Según Enrique Otte, Giovanni Antonio Picolomini y Scipione Pechi, fueron los mercaderes de nación sienesa más importantes de los establecidos en Sevilla ${ }^{54}$. El primero pudo llegar a la ciudad con el Arzobispo Alonso Manrique en 1523, pues era su mayordomo. Quizás fuera el propio prelado quien pusiera en relación a los sieneses con Alonso de Oviedo, pues el platero actuó en ocasiones como intermediario del prelado y en el cobro de rentas episcopales. Así, en 1527, adquirió para el mismo un rubí55 y en 1532 se ocupa del cobro de 35.000 maravedís que le debían por un juro de privilegio que le había hecho el $R_{e y}{ }^{56}$.

El encargo que recibe Oviedo en calidad de factor de la operación y el desarrollo de la misma hasta acabar en un largo y prolongado pleito que continuaba en 1534, figura detallada en un abultado expediente del Archivo General de Indias que recoge el proceso judicial, pruebas, declaraciones de multitud de testigos presentados por ambas partes y sentencias parciales ${ }^{57}$. El objeto central del proceso es la devolución de 14 onzas y una ochava de perlas (406,09 gramos) que a finales de 1529 había enviado desde Santo Domingo Alonso de Oviedo a Picolomini, para su

53 Juan Antonio Picolomini, mayordomo del arzobispo de Sevilla, apela al Consejo la sentencia dictada por los jueces de la Contratación en el pleito que Alonso de Oviedo, platero, vecino de Sevilla, le puso sobre la propiedad de unas perlas. Fecha de inicio: 153101 04. AGI, J, 707, N. 1, 6 piezas sin foliar. El documento fue citado por Otte, Las perlas del Caribe, 69, sin apenas profundizar en el.

54 Otte, Sevilla, siglo XVI, 301.

55 AHPS, NS, leg. 3267, of. 5, f. 283r. 1527-II-4.

56 AHPS, NS, leg. 3291, of. 5, f. roto. 1532-I-29.

57 AHPS, NS, leg. 3267, of. 5, f. 338r. 1527-II-9. 
venta. Sin embargo, éste entiende que son de su propiedad, como resultado las mercaderías enviadas a Cubagua. De esta forma se inicia el pleito, en el que cada uno argumenta su derecho sobre las perlas. Primero los jueces de la Casa de la Contratación se pronunciaron a favor del platero, pero de inmediato, en 1531, el sienés recurre ante el Consejo de Indias, sin que conozcamos el desenlace final.

En el verano de 1528, una vez constituida la compañía entre Picolomini y Pechi, según avanzamos, ambos mercaderes deciden contratar a Oviedo como factor de las operaciones comerciales inherentes a la misma, así como el rescate de perlas y adquisición de otras mercancías en la Española. Se estimaban precisos unos dos años para dar cumplimiento a los objetivos económicos. La confianza de los sieneses en el platero estaba fuera de toda duda, por su experiencia en tratos, especialmente en relación con el Nuevo Mundo, y su honradez, o al menos así lo exponen cuando pocos días antes de partir, en abril de 1529, le otorgan poder para que se haga cargo del negocio de perlas y dicen de él «[...]ser como es buena persona e de buena conçiençia e esperta e tal de quien sus majestades e nosotros rreçibiremos mucho provecho en la negoçiaçion suso dha[...] $\|^{58}$. Otra de las causas que parece fueron decisivas a la hora de justificar su elección era el estado calamitoso en que se encontraba Oviedo, prácticamente arruinado por las numerosas deudas que había contraído en distintas operaciones comerciales y financieras, que ascendían hasta los 574.581 maravedís. Así lo indican ambos en una de tantas declaraciones, cuando alegan que «[...] estaba pobre e quebrado e retraido, por muchas debdas que debía [...]» ${ }^{59}$, circunstancia que demuestran los distintos documentos aportados como prueba de las obligaciones de pago (cuadro 1) ${ }^{60}$. Quizás un exceso de confianza le había llevado a esta situación, de manera que en estos instantes era del todo insolvente, circunstancia que aprovecharían los italianos para embarcarle en esta difícil e incierta empresa que pronto, antes de zarpar, se complicaría aún más. El propósito inicial de los

58 AHPS, NS, leg. 3277, of. 5, f. 287r. 1529-IV-13.

59 AGI, J, 707, N. 1, pieza 4, s/f.

60 En total hemos contabilizado 19 acreedores. Véase cuadro 1. 
mercaderes era hacer uso de la licencia real para el «rescate» de perlas y aprovechar la venta de las abundantes mercaderías que Oviedo transportaría en la carabela (Santa Ana) y el galeón (San Andrés), ambos comprados por él en nombre de la compañía, por un total de 1.088.000 maravedís. Grandes serían las expectativas de Picolomini y Pechi, cuando asumen y se comprometen con el platero a saldar todas sus deudas a cambio de sus servicios y un salario de 600 pesos de oro (247.000 maravedís $)^{61}$.

\begin{tabular}{|c|c|c|c|c|}
\hline ACREEDOR & IMPORTE & $\begin{array}{c}\text { PRODUCTO O } \\
\text { MOTIVO }\end{array}$ & $\begin{array}{c}\text { FECHA DE } \\
\text { COMPROMISO }\end{array}$ & $\begin{array}{c}\text { PLAZO DE } \\
\text { DEVOLUCIÓN }\end{array}$ \\
\hline $\begin{array}{l}\text { Juan Marroquí y } \\
\text { Juan de Palma, } \\
\text { plateros }\end{array}$ & $\begin{array}{l}70.475 \\
\text { mrvs. }\end{array}$ & $\begin{array}{l}\text { Ciertas perlas y } \\
\text { aljófar }\end{array}$ & 1528-VII-2 & \\
\hline $\begin{array}{l}\text { Diego Sánchez de } \\
\text { Toledo, mercader. }\end{array}$ & $\begin{array}{l}45 \text { ducados } \\
(16.875 \\
\text { mrvs.) }\end{array}$ & $\begin{array}{l}\text { Dos esmeraldas } \\
\text { y un barril de } \\
\text { perlas, todo } \\
\text { engastado en oro. }\end{array}$ & 1528-IX-7 & 1 año. \\
\hline \begin{tabular}{|l|} 
Alfonso de la \\
Serna, mercader. \\
\end{tabular} & $\begin{array}{l}26.167 \\
\text { mrvs. }\end{array}$ & Cierto aceite. & $1528-\mathrm{X}-15$ & 8 meses. \\
\hline $\begin{array}{l}\text { Francisco de } \\
\text { París, mercader. }\end{array}$ & $\begin{array}{l}11.250 \\
\text { mrvs. }\end{array}$ & $\begin{array}{l}\text { Un contrato } \\
\text { público. }\end{array}$ & ¿1528? & \\
\hline $\begin{array}{l}\text { Diego Pachón, } \\
\text { mercader. }\end{array}$ & $\begin{array}{l}58.690 \\
\text { mrvs. }\end{array}$ & $\begin{array}{l}\text { Un contrato } \\
\text { público. }\end{array}$ & $1528-\mathrm{X}-7$ & \\
\hline $\begin{array}{l}\text { El jurado } \\
\text { Francisco de la } \\
\text { Corona. } \\
\end{array}$ & $\begin{array}{l}114.356 \\
\text { mrvs. }\end{array}$ & $\begin{array}{l}\text { Sedas y } \\
\text { terciopelos. }\end{array}$ & 1528-VI-18 & 7 meses. \\
\hline $\begin{array}{l}\text { Alonso Bernal, } \\
\text { platero. }\end{array}$ & $\begin{array}{l}30 \text { ducados } \\
(11.250 \\
\text { mrvs.) }\end{array}$ & $\begin{array}{l}\text { Ciertos jaeces de } \\
\text { cobre dorado y } \\
\text { unas cabezadas } \\
\text { de plata. }\end{array}$ & 1528-XII-16 & 4 meses. \\
\hline $\begin{array}{l}\text { Desconocido } \\
\text { (empeñados) }\end{array}$ & $\begin{array}{l}71.692 \\
\text { mrvs. }\end{array}$ & Ciertos lienzos. & & \\
\hline
\end{tabular}

61 Puesto que es la primera vez que citamos un apunte en esta moneda, hemos de aclarar que para su conversión en maravedís empleamos la equivalencia que muestran los documentos de compraventa, débito, contratos, operaciones financieras en general de las notarías sevillanas en los años veinte y treinta del XVI, esto es 450 maravedís por peso de oro. En realidad, se trata de un cómputo empleado principalmente en transacciones u operaciones pagaderas en territorio americano, en lingotes o pasta de oro, «de minas, fundido y marcado». Siempre, en estas décadas, se especifica esta equivalencia. No olvidemos el esfuerzo de las autoridades monetarias del Emperador, en garantizar la máxima estabilidad del patrón oro. Véase al respecto Earl J. Hamilton, El tesoro americano y la revolución de los precios en España, 15011650, (Barcelona: Crítica, 2000), 44-45, n 107. Guillermo Céspedes del Castillo, Las Casas de Moneda en los Reinos de Indias. Las cecas indianas en 1536-1825, vol. I (Madrid: Museo Casa de la Moneda, 1996), 27-28 y 33-34. 


\begin{tabular}{|c|c|c|c|c|}
\hline ACREEDOR & IMPORTE & $\begin{array}{c}\text { PRODUCTO O } \\
\text { MOTIVO }\end{array}$ & $\begin{array}{c}\text { FECHA DE } \\
\text { COMPROMISO }\end{array}$ & \begin{tabular}{|c|} 
PLAZO DE \\
DEVOLUCIÓN
\end{tabular} \\
\hline $\begin{array}{l}\text { Domingo de } \\
\text { Zornoza }\end{array}$ & $\begin{array}{l}22.120 \\
\text { mrvs. }\end{array}$ & & & \\
\hline Alonso de Solana & $\begin{array}{l}7 \text { ducados } \\
(2.625 \\
\text { mrvs. }) \\
\end{array}$ & & & \\
\hline Andrés de Osarga & 8.000 mrvs. & & & \\
\hline $\begin{array}{l}\text { Juan Antonio } \\
\text { Picolomini y } \\
\text { ScipionPechi. }\end{array}$ & $\begin{array}{l}14.670 \\
\text { mrvs. }\end{array}$ & $\begin{array}{l}\text { Mercaderías, } \\
\text { seguros y averías } \\
\text { de mercaderías } \\
\text { que llevó a } \\
\text { Cubagua. }\end{array}$ & & \\
\hline $\begin{array}{l}\text { Segismundo de } \\
\text { Benasay }\end{array}$ & \begin{tabular}{|l|}
34.151 \\
mrvs.
\end{tabular} & & & \\
\hline $\begin{array}{l}\text { Juan Antonio } \\
\text { Picolomini y } \\
\text { ScipionPechi. } \\
\end{array}$ & 6.280 mrvs. & Cebada. & & \\
\hline $\begin{array}{l}\text { Diego Sánchez de } \\
\text { Toledo }\end{array}$ & \begin{tabular}{|l}
16.850 \\
mrvs.
\end{tabular} & Contrato público. & & \\
\hline $\begin{array}{l}\text { Juan Antonio } \\
\text { Picolomini y } \\
\text { ScipionPechi. }\end{array}$ & $\begin{array}{l}26.667 \\
\text { mrvs. }\end{array}$ & $\begin{array}{l}\text { Alquiler de la } \\
\text { casa donde vivía, } \\
\text { de Martín de } \\
\text { Orduña. }\end{array}$ & & \\
\hline \begin{tabular}{|l|} 
Cebrián de \\
Caritate
\end{tabular} & 3.660 mrvs. & Trigo. & 1529-IV-25 & \\
\hline Leonardo Cataño. & 2.553 mrvs. & & & \\
\hline $\begin{array}{l}\text { Cristóbal } \\
\text { Gutiérrez de San } \\
\text { Vítores. } \\
\end{array}$ & $\begin{array}{l}56.250 \\
\text { mrvs. }\end{array}$ & $\begin{array}{l}\text { Ciertas } \\
\text { mercaderías. }\end{array}$ & & \\
\hline TOTAL DEUDA: & \begin{tabular}{|l|}
574.581 \\
mrvs. \\
\end{tabular} & & & \\
\hline
\end{tabular}

CUADRO 1. Deudas contraídas por Alonso de Oviedo antes de partir a Cubagua en abril de 1529 .

Fuente: AHPS, NS, of. 5 (1528-1529).

Tuvieron todo el otoño y parte del invierno para preparar la empresa y adquirir mercancías, pensadas fundamentalmente para aprovisionar la desértica isla de Cubagua, como dio a conocer Enrique Otte ${ }^{62}$. A finales de 1528 un nuevo elemento debió sumarse al plan inicial de los sieneses, que orientaría a la compañía de forma clara al negocio perlífero.

62 El cargamento reunía vino, aceite, comestibles, ropa, telas, jabón, instrumentos metálicos, algunos retablos pictóricos, rosarios, una vihuela y seis libros de lectura. Otte, Las perlas del Caribe, 489-492. 
A la sociedad mercantil y de rescate del, definido por Otte, como "grupo sevillano-cubagüense», se suma un milanés, Luigi Lampignano (Luis de Lampiñán en la documentación sevillana), mercader y fabricante de ingenios, quien tuvo autorización de Carlos $\mathrm{V}$ para ensayar un nuevo método para el rescate de perlas en Cubagua, una especie de barra de arrastre, nombrada «rastro» que, literalmente, arrancaba las ostras del fondo marino con mayor eficacia que los buceadores, impulsada por dos embarcaciones y que se esperaba diera alto rendimiento ${ }^{63}$. El tantas veces nombrado Otte estima, no obstante, que el convenio de Lampiñán con los sieneses se había establecido en el primer concierto de 28 de agosto ${ }^{64}$; sin embargo, la documentación inédita que hemos manejado, deja ver que fue más adelante cuando el milanés se interesó por la infraestructura náutica y mercantil de Picolomini y Pecci. Si bien Lampiñán gozaba de licencia para su empresa del «rastro de perlas» desde enero de 1528, no sería hasta el 7 de febrero de 1529 cuando el Rey emite real cédula otorgando licencia a Picolomini y Lampiñán para enviar los dos navíos directos a Cubagua, retornando por Santo Domingo, a la vez que aplicar el nuevo sistema de $\operatorname{arrastre}^{65}$. Entonces se precipitan los contratos de marineros y los poderes para emprender cuanto antes la expedición. El 17 de febrero los tres italianos, sieneses y milanés, pactaron la compañía mixta comercial y «rescatadora» y a continuación contratan a Pedro, Alonso y Juan Ruano, Rodrigo de Arnero y Cristóbal Díaz, marineros vecinos de Ayamonte, como encargados por dos años de dirigir las operaciones de extracción de perlas aplicando el «rastro»

63 No fue el único ingenio creado para la más cómoda y rentable extracción de las ostras anteriormente, hacia 1505, Alonso de Ojeda ensayó un modelo de rastro usado en las costas de Andalucía Occidental. En 1520 se registra el intento de mecanizar la extracción, de Juan de Cárdenas, piloto residente en Sevilla, que obtuvo licencia real. Véase: Manuel Luengo Muñoz, «Inventos para acrecentar la obtención de perlas en América, durante el s. XVI,» Anuario de Estudios Americanos, t. IX, (1952): 51-72. Otte, «El proceso del rastro», 386-406. José Luis Torres Merino, Cubagua y su riqueza perlífera. Génesis del poblamiento de Suramérica (Madrid: Punto Rojo Editorial, 2018), 116-135. Warsh, American baroque, 61-71.

64 Otte, «El proceso del rastro», 386-387. La compañía estuvo activa entre el 28 de agosto de 1528 y el 8 de julio de 1529. Las decisiones y contrataciones estaban por entero en manos de Picolomini.

65 «Licencias para enviar navíos a Cubagua», Toledo, 1529-II-7, Archivo General de Indias (AGI), Sevilla-España. Sección Panamá, 234, L.3, ff. 280v.-281v. 
de Lampiñán y los días que no fuera posible, navegarían hasta la costa de Cumaná para aprovisionar agua, leña y bastimentos ${ }^{66}$. Pero el capital aportado por los tres socios principales no era suficiente, de manera que otros italianos deciden aportar liquidez al proyecto, como fue el caso del mercader sienés, César Bonensene, quien invierte 200 ducados de oro, y el florentino Jácome Fantoni cede dos esclavos negros de su propiedad, para trabajar en la compañía del «rastro», a la vez que son contratados más marineros que colaboren en el "rastreo» de perlas ${ }^{67}$. Todo esto cuando faltaba menos de un mes para zarpar, lo cual viene a demostrar el retardo en la unión de los sieneses al proyecto de Lampiñán. Ante estas circunstancias, la misión de Oviedo no se altera, actuaría como factor de las operaciones comerciales asumiendo la dirección del rescate perlífero, en caso de muerte de Lampiñán.

Aunque no es el objeto de estas líneas profundizar en el sistema del milanés para rastrear los fondos marinos de Cubagua, conocemos a partir de las investigaciones de Otte, que la iniciativa pese a la autorización real y la fortaleza de su infraestructura humana y económica, fracasó por completo, habida cuenta de la frontal oposición de los habitantes y empresarios del «rescate» de Nueva Cádiz quienes, esgrimiendo razones que hoy se nos antojarían ecológicas, recurren ante la Real Audiencia dominicana, por el grave daño que este método de dragado suponía para la preservación de los placeres de ostras, pues no sólo arrancaban las potencialmente provistas de perlas, sino también las de menor tamaño, aún en desarrollo y hasta las algas que proveían su alimento, alegando alguno de los informantes "[...]que el dicho rastro lo destruye e consume

66 AHPS, NS, leg. 3276, of. 5, ff. 381r.-384v. 1529-II-17 y 1529-II-18.

67 El empleo de esclavos negros como buceadores se hizo cada vez más importante en esta inhumana empresa, sustituyendo a los indios a mediados de siglo. Así lo reflejan muchos testimonios gráficos y pinturas de los siglos XVI y XVII, siendo estas una de las primeras tareas en las que fueron explotados los africanos en América. Kevin Dawson, "Enslaved swimmers and divers in the atlantic world," The Journal of American History Vol. 92, $\mathrm{n}^{\circ} 4$ (2006): 1327-1355. Jean Pierre Tardieu, «Perlas y piel de azabache. El negro en las pesquerías de las Indias Occidentales,» Anuario de Estudios Americanos Vol. 65, n 2 (2008): 91-124. 


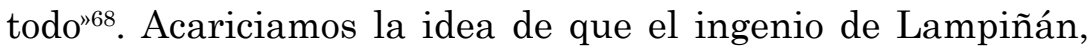
unido a los evidentes intereses económicos, puede ponerse en relación con uno de los aspectos que más admiraron los europeos del XVI de las perlas, como tesoros marinos, y no era otro que el sufrido e inhumano método para su obtención, el buceo a pulmón practicado por indios y, desde muy pronto, por esclavos africanos, tal como describieron cronistas y reflejaron en sus obras algunos pintores y grabadores europeos del XVI ${ }^{69}$.

A poco de llegar a Cubagua, Alonso de Oviedo sustituye a Lampiñán al frente de la compañía del rastro de perlas, pues este último se dirige inmediatamente a Santo Domingo, para reclamar el cumplimiento de la real provisión por parte de las autoridades insulares. Oviedo asume presentar una información probatoria sobre la pesca de perlas en Cubagua, aportando una serie de testigos que informan fundamentalmente sobre lugares y profundidades frecuentadas por los vecinos de Nueva Cádiz ${ }^{70}$. Nada más sabemos de la actividad del platero, que suponemos se centraría en la venta de las mercaderías que traía el galeón San Andrés, y en la compra, quizás también rescate, de algunas perlas. A finales de 1529 marcha a Santo Domingo, continuando con su periplo mercantil donde tampoco podemos seguir sus pasos, pero, podemos intuir, unido al beneficio de parte de las mercaderías transportadas desde Sevilla, se ocuparía de asuntos personales, relacionados con el mencionado ingenio azucarero de Bonao, el cobro de ciertas cantidades según poderes que traía, la liquidación de sus

68 En principio los vecinos se oponen a que se utilice el rastro o draga en profundidades menores a las 8 o 10 brazas, máximo que alcanzan los indios buceando, y se delimite una zona cuya profundidad supere las 10 o 12 brazas, aunque recelan del poder destructivo en grandes profundidades, donde no se encuentran tantas ostras y que con el tiempo se adentren en la zona delimitada para los vecinos. Sobre el proceso, Otte, «El proceso del rastro», 386-406.

69 Mónica Domínguez-Torres, «Pearl fishing in the Caribbean. Early images of slavery and forced migration in the Americas,» en African diáspora in the cultures of Latin America, the Caribbean and the United States, coord. Persephone Braham (Newark: University of Delaware Press, 2015), 73-82. Warsh, American Baroque, 112117. Mónica Domínguez-Torres, «"Nel piu ricco paese del mondo”. Cubagua Island as an epicenter of the early atlantic trade," en Circulación: Movement of Ideas, Art, and People in Spanish America, coord. Jorge Rivas (Denver: Denver Art Museum, 2018), 14-39.

70 Otte, «El proceso del rastro», 386-406. 
propios negocios y adquisición de mercaderías como cueros, cañafístola o azúcar.

Conocemos algunos hechos relacionados con su actividad y el brusco abandono de La Española, a manos de la justicia, que le remite a Sevilla para ser juzgado y cumplir condena, en diciembre de 1530. Según declaraciones del propio Oviedo, fechadas el 28 de enero de 1531, cuando permanecía preso en la cárcel del Consejo de Indias en Sevilla, en noviembre del año anterior fue preso en Santo Domingo y trasladado a Sevilla, donde llegó el día 24 de diciembre de 1530, siendo encaminado desde la nao que le llevaba al citado centro penitenciario. Según se desprende de estas declaraciones, año y medio después de iniciada la empresa, Scipione Pechi y Juan Antonio Picolomini que aún no han recibido beneficio alguno de la compañía, deciden demandar a Oviedo y exigirle el pago de 452.000 maravedís, importe de las deudas que en su ausencia han satisfecho los sieneses en su nombre, tal como habían convenido al concertar los servicios del platero. Además, le reclaman 300 pesos de oro (135.000 maravedís), beneficio estipulado de la venta de las mercancías que había transportado a las Antillas, descontados ya los gastos ocasionados por el viaje y pago de almojarifazgo ${ }^{71}$. Señalamos que, en este año, a lo largo de 1529-30 Oviedo envió algunas mercancías no especificadas a Sevilla, pues tiempo después la Casa de la Contratación le exige el pago del correspondiente almojarifazgo ${ }^{72}$.

En febrero de 1531 Oviedo abandona la cárcel después de firmar un compromiso de pago, comprometiéndose a saldar la deuda con Pechi y entregándole en prenda a modo de garantía, un rubí grande, cortado en tabla, un diamante en punta y una turquesa pequeña, que le serían restituidos al quedar saldada la deuda. En esos mismos instantes se inicia el largo pleito,

71 AGI, J, 707, N. 1, pieza 1, s/f. No podemos precisar folios, pues la totalidad del expediente que relata el proceso carece de foliación. Consta de 6 piezas.

72 Real Cédula a los Oficiales de la Casa de la Contratación para que cobren de Juan Antonio Picolomini, cierta cantidad de oro que debe del almojarifazgo de mercancías que le remitieron de Cubagua sus factores Alonso de Oviedo y Juan de Medina. «Cobro de deuda a Juan Antonio Picolomini», Madrid, 1532-XII-10, Archivo General de Indias (AGI), Sevilla-España. Sección Indiferente, 1961, L.2, f. 245r.-v. 
cuyo objeto principal fue la demanda que plantea el platero a Picolomini, sobre la devolución de las ya aludidas 14 onzas y una ochava de perlas, que Oviedo había enviado de Santo Domingo en diciembre de 1529, en la "nao de los alemanes», para que las vendiera y le reservara el importe. El sienés entiende el envío, como propiedad de la compañía mercantil, de manera que puede disponer del mismo libremente. En 1531 los jueces de la Casa de la Contratación emiten sentencia favorable a Oviedo, pero inmediatamente sería recurrida por Picolomini, alegando el pago de deudas personales del platero, la renta de su casa sevillana y la manutención de su esposa en su ausencia, como argumentos para justificar su derecho sobre las perlas ${ }^{73}$.

No podemos pronunciarnos sobre a quien asiste la razón sobre las perlas, pues desconocemos el fallo final del proceso, que estimamos pudo acabar en nueva sentencia favorable a Oviedo, como da a entender la buena organización de su defensa, selección de testigos informantes y apreciaciones de los jueces del Consejo. Veamos lo que sabemos de aquellas perlas que tanto revuelo e interés despertaron en Sevilla en 1530, y acabaron en manos de un mercader italiano estante en España, Micer Nicolao Forneli, Fornici o Fantoni, según nombran diferentes testigos, quien las adquirió perforadas y ensartadas, en 700 ducados de oro (262.500 maravedís) ${ }^{74}$. Multitud de personas, que ahora actúan como declarantes en las distintas etapas del pleito, vieron y apreciaron las perlas, algunos intentaron comprarlas, pero finalmente desistieron y hasta fueron debidamente horadadas para ensartarlas, por el horadador de perlas Juan de Barahona, quien percibió por ello 3.442 maravedíes $^{75}$. Todos los testigos ${ }^{76}$ coinciden en la excepcional calidad de las mismas, en su buen tamaño, esfericidad, brillo y lustre, si bien hay variaciones en cuanto

73 AGI, J, 707, N. 1 , piezas 1 y 2 , s/f.

74 AGI, J, 707, N. 1, piezas 2 y 4, s/f.

75 AGI, J, 707, N. 1, pieza 4, s/f.

76 AGI, J, 707, N. 1, pieza 4, s/f. Entre los testigos aportados por Picolomini figuran los plateros Fernando de Antezana, Juan Ruiz «el Vandalino», quien declara tener 28 años, y Alonso Fernández, alcalde del gremio. También declararon Scipion Pechi y Diego Fernández, notario de la mesa arzobispal. 
a su quilataje. El platero Antonio Castro declaró que todas eran redondas, buenas, grandes, pero también chicas ${ }^{77}$. Tanto el citado horadador Juan de Barahona como Cristóbal de Barahona, del mismo oficio, probablemente su hermano, contaron las perlas y no se aclaran si eran 1.511 ó 1.513 , como tampoco los oficiales de la Casa de la Contratación, que fueron los primeros en contemplarlas en Europa. En el también horadador Bernaldo de Montemayor recayó el encargo de agruparlas en distintas calidades, entonces llamadas "suertes", paso previo a su valoración monetaria. Sin cuantificarlas en grupos, estableció que todas iban de "más que primera», o de excepcional calidad y tamaño, hasta "tercera suerte», todavía de apreciable tamaño y valor ${ }^{78}$.

Esta clasificación en suertes de las perlas, basándose en su redondez, diámetro y lustre, es la primera vez que sale a relucir. Con mayor precisión lo vemos en algunos instrumentos notariales, que contabilizan y valoran compraventas de perlas o aljófar, como el otorgado en 1528 por el mercader Fernán Pérez de Jarada, quien deposita en manos de su hermano Alonso Pérez de Jarada, abundantes perlas y aljófar, para que las llevara a Valencia y otros lugares de Aragón, donde habrá de venderlas. En esta ocasión, a las más grandes se otorgó la calificación de «más de primera suerte» y luego hasta la «octava suerte». Este documento, que brinda igualmente el peso de cada suerte en onzas y ochavas, como era preceptivo, y su equivalencia en maravedís ${ }^{79}$, nos aclara la posible clasificación de las perlas en ocho suertes y las últimas, quizás a partir de la quinta, entrarían ya en la categoría de aljófar. El procedimiento debió ser ideado en el contexto humano y profesional de los plateros, cambiadores y mercaderes sevillanos del momento, para evitar las imprecisas y convencionales tipificaciones

77 AGI, J, 707, N. 1, pieza 4, s/f.

78 AGI, J, 707, N. 1, pieza 4, s/f. Del mismo modo las calificó el corredor de lonja Domingo Postigo.

79 AHPS, NS, leg. 3273, of. 5, f. 1r.1528-III-16. A partir de la información aportada por este valioso documento podemos establecer los precios por onza (28,75 gramos) de distintas suertes para ese año de 1528, período álgido en la producción de perlas en Cubagua. Más que primera: 1050 mrvs. Primera: 1.000 mrvs. Segunda: 900 mrvs. Tercera: 750 mrvs. Cuarta: 690 mrvs. Quinta: 510 mrvs. Sexta: 500 mrvs. Séptima y octava: 380 mrvs. 
empleadas en las Antillas e incluso en Sevilla, por los oficiales reales y particulares, de las que ha dado cuenta Otte ${ }^{80}$. Una vez acordada una ordenación más precisa, por suertes, resultaba más fácil la valoración en maravedís de cada marco, onza u ochava. El término "suerte», debe coincidir aproximadamente con el de «quilate», ya mencionado por Fernández de Oviedo en relación con las perlas de Cubagua, a las que califica de muy pequeñas, la mayoría inferior a los cinco quilates ${ }^{81}$. Sin duda, la agrupación por quilates (del 1 al 10), su equivalencia en las citadas unidades de peso y el correspondiente valor en reales quedaría regulado por el platero Juan de Arfe, en su célebre Quilatador de la plata, oro y piedras, cuya edición príncipe data de $1572^{82}$. Es posible que el sistema de «suertes» empleado por el mercado sevillano de los años veinte y treinta del siglo, no fueran si no un primer ensayo fundamentado en quilates, luego precisado por Arfe, aunque en orden inverso, según se puede ver en el instrumento quilatador que ilustra en el expresado tratado, con tamaños de 1 a 10 quilates $^{83}$.

Picolomini intentó en varias ocasiones vender las perlas, antes de que Oviedo las reclamara, pretendiendo por ellas una suma que ascendía, al menos a 850 ducados de oro. Sin embargo, las ofertas fueron inferiores, el corredor de lonja Domingo Postigo y el mercader Luis Sánchez ofrecieron 500 ducados (187.500 maravedís). Se desestimaron ofertas del valenciano Luis Torregrosa, del platero Antonio Castro, del

\footnotetext{
80 Términos como pedrería, aljófar grosero, aljófar menudo, granujones, pinjantes, avemarías, asientos, berruecos, topos, cadenilla, aluden más bien a la percepción visual y formal del producto que a su adecuada clasificación y valoración en metálico. Otte, Las perlas del Caribe, 36-41.

81 «[...] y muchas de aquellas perlas eran muy buenas e orientales e redondas, aunque pequeñas, porque ninguna [...] avía que llegasse a çinco quilates». También valora en quilates las grandes perlas encontradas en la costa de Panamá y vuelve con las de Cubagua para afirmar, "[...] pero en estotra isla de Cubagua [...] no son tamañas, sino pequeñas, de dos y tres e cuatro o çinco quilates, o poco más la mayor dellas; pero en perfiçion algunas, e innumerable cantidad de aljophar grueso y menudo y de todas suertes». Observamos la introducción del concepto "suerte», quizás según este autor, preferentemente aplicado al aljófar, mientras para las buenas perlas se aplica el quilataje. Gonzalo Fernández de Oviedo y Valdés, Historia general y natural de las Indias (Madrid: Real Academia de la Historia, $1^{a}$ parte, 1851), 591 y 605.

82 Juan de Arfe y Villafañe, Quilatador de la plata, oro y piedras (Valladolid: Alonso y Diego Fernández de Córdoba, 1572), 64v.-67r.
}

83 Arfe, Quilatador, 67r. 
mercader de perlas Juan de Buendía, quien ofertó hasta 700 ducados y hasta fueron enviadas al banquero cortesano Diego de la Haya, quien no logra enajenarlas por 800 ducados. Así las cosas, el mencionado mercader italiano, Micer Nicolao, las adquiere en 700 ducados, importe que pretende recuperar Alonso de Oviedo, sin dejar de quejarse del eximio precio en el que fueron vendidas sus «queridas» $\operatorname{perlas}^{84}$.

\section{Conclusiones}

La figura de Alonso de Oviedo se acomoda con precisión al contexto mercantil de la Sevilla de la primera mitad del XVI, cuando su puerto e infraestructuras comerciales ocupaban uno de los primeros puestos de Europa. Responde al prototipo de profesional multifacético, artista, mercader, emprendedor arriesgado, hasta ahora olvidado. Su inserción en este marco humano y económico viene a demostrar la vitalidad y oportunidades que del mismo derivaban, especialmente para quienes, como los plateros u orfebres, estaban familiarizados con los metales, perlas y piedras preciosas, empleados como bienes suntuarios, pero también como moneda de cambio. No debe extrañar la permeabilidad de fronteras entre la platería y el comercio, no sólo demostrado por la documentación como la aquí analizada, sino también por otras circunstancias de la realidad urbana de Sevilla, como puede ser el establecimiento del arte de la platería sevillano y sus artífices, en el centro neurálgico del mercantilismo, el entorno o gradas de la catedral, donde habitaban y negociaban a diario mercaderes, corredores, banqueros, etc.

Desde el punto de vista social, frente a la nobleza terrateniente poderosa en lo económico, político y militar durante la edad media, el entramado humano con el que se relaciona Oviedo y las operaciones financieras y mercantiles que practica, pone de relieve el ascenso y progresivo posicionamiento entre los estratos más altos de la sociedad, de un nuevo sector que es el de los mercaderes, banqueros, factores, intermediarios, plateros, por cuyas manos pasan

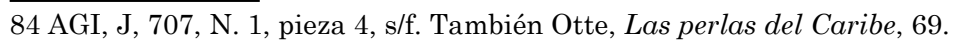


tanto los riesgos como las ganancias generadas por las prácticas económicas de actualidad, abiertas a un espectro humano mucho más amplio que en tiempos medievales. El ascenso, al menos en lo que a riqueza se refiere, el control de diferentes segmentos de esta poderosa y creciente fuente de riqueza, va a estar desvinculada del poder aristocrático y la realeza, ofreciéndose a personas que, como Oviedo, no temen los riesgos, la aventura, las relaciones con un variado elenco de personajes que controlan las diferentes facetas del sistema pre capitalista y procuran el bienestar, hasta ahora exclusivo de las capas más altas de la sociedad estamental. En el nuevo modelo de hombre de negocios que vemos en la Sevilla del XVI, destacaron conversos habituados al trabajo de los metales, su ensaye y valoración, los préstamos, a fin de cuentas continuadores del espíritu empresarial sefardita, ajenos a la cotidiana condena de los intercambios y la obtención de ganancias que proviene de la mentalidad escolástica todavía vigente en la ideología religiosa del momento. Quién sabe si el propio Oviedo fuera descendiente de judeoconversos, cosa que no sería extraña.

Al igual que otros casos ya conocidos, Oviedo simultaneó la actividad artística con la inversión mercantil. Salta a la vista en este personaje la importancia que entonces tuvieron unas adecuadas relaciones y contactos humanos, con mercaderes de distintos ámbitos peninsulares, italianos, flamencos, ingleses, alemanes, todos ellos representados en la urbe hispalense, además de cambiadores o banqueros, corredores de lonja, maestres y señores de naves, sin olvidar el cotidiano trato con los colegas de su oficio de platero. Las múltiples facetas de su quehacer quedaron reflejadas en las líneas que preceden, si bien queremos subrayar, tal como vimos, el dominio de las prácticas de la navegación y conocimiento de embarcaciones, otro valor añadido a sus habilidades, buen reclamo para mercaderes. El mismo, según analizamos, se encargó de proveer la carabela y el galeón precisos para la empresa de Cubagua y actuó como maestre de una de las naves, poniendo así de relieve sus dotes para el gobierno de la singladura atlántica, salvaguardando todos los intereses y vidas en ella inmersos. 
Uno de los aspectos más interesantes que hemos intentado subrayar de la trayectoria vital de Oviedo, es su vocación americana. Al Nuevo Mundo dirigió preferentemente sus empresas comerciales y hasta allí viajó, dejándose persuadir por los productos de aquellas tierras, entre los que hemos destacado el azúcar y, especialmente, las perlas, con las que traficó en repetidas ocasiones, hasta llegar a entablar un largo pleito para reclamar las que entendía eran de su propiedad. Hay que sumarle a los especializados mercaderes y traficantes de perlas y aljófar que tanto "ruido» hicieron en la capital andaluza, por los astronómicos capitales que movieron, como Diego Caballero, Juan de Buendía, los plateros Juan de Córdoba, Gonzalo de Toledo y su hijo Diego, los italianos Cattaneo (Cataño), el inglés Robert Torne, los alemanes Juan Pruner y, sobre todo, Lázaro Nürnberger, máximo traficante y experto en perlas en la Europa de la época, cuyo establecimiento en Sevilla viene a decir mucho del protagonismo de la urbe como centro receptor y distribuidor de perlas. Todos ellos hicieron posible la circulación del preciado y fascinante producto suntuario, por los más alejados rincones de Europa, contribuyendo a difundir el misterio y atractivo de las perlas caribeñas y su empleo como moneda de cambio, en una importancia próxima a la del oro y la plata. Sin embargo, seguimos sin poder determinar, por falta de información precisa, que uso harían de las perlas y el aljófar plateros como Alonso de Oviedo, bien como complemento de piezas de platería o para su empleo en joyería. De momento, la documentación manejada solo deja ver la compraventa de las mismas en virtud de los generosos márgenes de ganancias que generan, sin aportar nada más. Habida cuenta del constante empleo del producto en la joyería renacentista, es fácil intuir que muchos de estos artífices comprarían, en ocasiones, diferentes tipos de perlas para su uso en las manufacturas del oficio.

En última instancia, la figura de Oviedo hay que sumarla a otros plateros-mercaderes y prestamistas de la primera mitad del XVI, como Juan de Córdoba, el primero documentado en relación con el tráfico mercantil americano, Diego de Vozmediano, Juan y Martín de Oñate, Francisco de Castro o Juan Ruiz «el Vandalino», artistas y comerciantes 
que alternan a lo largo de su trayectoria vital, el ejercicio de la profesión contratando obras específicas como custodias o ajuares para iglesias, la catedral, particulares o para remitir a Indias, constituyendo incluso compañías laborales, a la vez que periódicamente, la mayoría con bastante frecuencia, ejercen en la actividad mercantil en calidad de exportadores e importadores, intermediarios, agentes, prestamistas, compradores de oro y plata para amonedar, de perlas, etc. Todo ello constituye una nueva prueba de la ingente actividad comercial y profesional desempeñada en aquellos momentos por los integrantes del gremio de plateros sevillano, el más próspero entre los oficios artísticos de la "Sevilla americana». Los futuros estudios habrán de valorar esta faceta entreverada entre sus agremiados, tanto como el análisis formal y estilístico de sus producciones metálicas, poniendo así de manifiesto la evidente hermandad entre metales, piedras preciosas, perlas y economía.

\section{Referencias}

\section{Fuentes primarias}

Archivo General de Indias (AGI), Sevilla-España. Secciones Justicia, Indiferente, Panamá.

Archivo Histórico Provincial de Sevilla (AHPS), Sevilla-España. Sección Notarías de Sevilla.

Archivo del Instituto de Patrimonio Cultural de España, Madrid-España.

\section{Bibliografia}

Angulo, Diego. El Gótico y el Renacimiento en las Antillas. Sevilla: EEHA, 1947.

Arfe y Villafañe, Juan de. Quilatador de la plata, oro y piedras. Valladolid: Alonso y Diego Fernández de Córdoba, 1572.

Bernal, Antonio Miguel, Antonio Collantes de Terán, y Antonio GarcíaBaquero González. Sevilla, de los gremios a la industrialización. Sevilla: Ayuntamiento, 2008. 
Céspedes del Castillo, Guillermo. Las Casas de Moneda en los Reinos de Indias. Las cecas indianas en 1536-1825, vol. I. Madrid: Museo Casa de la Moneda, 1996.

Cruz Valdovinos, José Manuel. Cinco siglos de platería sevillana. Sevilla: Ayuntamiento, 1992.

Cruz Valdovinos, José Manuel, y Andrés Escalera Ureña. La platería de la catedral de Santo Domingo, primada de América. Madrid: Tabapress, 1993.

Dawson, Kevin. «Enslaved swimmers and divers in the atlantic world.» The Journal of American History, vol. 92, nº 4 (2006): 1327-1355.

Domínguez-Torres, Mónica. «Pearl fishing in the Caribbean. Early images of slavery and forced migration in the Americas.» En African diáspora in the cultures of Latin America, the Caribbean and the United States, coordinado por Persephone Braham, 73-82. Newark: University of Delaware Press, 2015.

. "Nel piu ricco paese del mondo". Cubagua Island as an epicenter of the early atlantic trade.» En Circulación: Movement of Ideas, Art, and People in Spanish America, coordinado por Jorge Rivas, 14-39. Denver: Denver Art Museum, 2018 .

Donoso Anés, Rafael. «Mercado y mercaderes de oro y plata de Sevilla en la segunda mitad del siglo XVI.» En Dinero, moneda y crédito en la monarquía hispánica, coordinado por Antonio Miguel Bernal, 213-239. Madrid: Marcial Pons, 2000.

Fernández de Oviedo y Valdés, Gonzalo. Historia general y natural de las Indias. $1^{a}$ parte. Madrid: Real Academia de la Historia, 1851.

García-Baquero González, Antonio. La Carrera de Indias: suma de la contratación y océano de negocios. Sevilla: Algaida y Expo 92, 1992.

Gestoso y Pérez, José. Ensayo de un diccionario de los artífices que florecieron en Sevilla. Vol. II. Sevilla: La Andalucía Moderna, 1900. 
Gil, Juan. Los conversos y la Inquisición sevillana. Vol. III. Sevilla: Universidad y Fundación El Monte, 2001.

Hamilton, Earl J. El tesoro americano y la revolución de los precios en España, 1501-1650. Barcelona: Crítica, 2000.

Heredia Moreno, María del Carmen. "Apuntes sobre el tráfico artístico con América en el siglo XVI. Artistas, artesanos y mercaderes en la Carrera de Indias.» En El arte español fuera de España, coordinado por Miguel Cabañas Bravo, 193-206. Madrid: CSIC, 2003.

Herrera García, Francisco Javier. «Platería y comercio en Sevilla durante la primera mitad del XVI: Juan Ruiz "el Vandalino" y su vertiente mercantil.» En La plata en Iberomérica. De los orígenes al siglo XIX, coordinado por Jesús Paniagua (en prensa).

Luengo Muñoz, Manuel. «Inventos para acrecentar la obtención de perlas en América, durante el s. XVI,» Anuario de Estudios Americanos, t. IX (1952): 51-72.

Otte, Enrique. «El proceso del rastro de perlas de Luis de Lampiñán.» Boletín de la Academia Nacional de la Historia, $\mathrm{n}^{\circ} 187$ (1964): 386-406.

Las perlas del Caribe: Nueva Cádiz de Cubagua. Caracas: Fundación John Boulton, 1977.

. Sevilla y sus mercaderes a fines de la Edad Media. Sevilla: Universidad y Fundación El Monte, 1996.

Sevilla, siglo XVI: materiales para su historia económica. Sevilla: Centro de Estudios Andaluces, 2008. Edición en PDF.

Palenzuela Domínguez, Natalia. «Los mercaderes y hombres de negocios burgaleses en Sevilla en tiempos de Isabel la Católica.» En Comercio y hombres de negocios en Castilla y Europa en tiempos de Isabel la Católica, coordinado por Hilario Casado y Antonio García-Baquero, 331-352. Madrid: SECC, 2007.

Palm, Erwin Walter. "The treasure of the Cathedral of Santo Domingo.» The Art Quarterly, no 13 (1950): 120-122. 
Palomero Páramo, Jesús Miguel. «La platería en la Catedral de Sevilla.» En La Catedral de Sevilla, coordinado por Diego Angulo, 575-645. Sevilla: Guadalquivir, 1991.

Santos Márquez, Antonio Joaquín. «Nuevas pruebas documentales de la implicación del arte de la platería hispalense en el tráfico comercial y artístico con las Indias (1530-1630).» En El tesoro del lugar florido. Estudios sobre la plata iberoamericana. Siglos XVI-XIX, coordinado por Juan Haroldo Roda y otros, 25-38. Ciudad de México: INAH; León: Universidad, 2017.

Sanz Serrano, María Jesús. La custodia procesional: Enrique de Arfe y su escuela. Córdoba: Cajasur, 2000.

. «Plateros de la Catedral de Sevilla en la primera mitad del siglo XVI y sus relaciones con América.» En Estudios de platería San Eloy, coordinado por Jesús Rivas, 717-738. Murcia: Universidad, 2010. . «Plateros sevillanos y estantes en Sevilla que comerciaban con América entre 1525 y 1550.» En Estudios de platería San Eloy, coordinado por Jesús Rivas, 555-570. Murcia: Universidad, 2015.

Tardieu, Jean Pierre. «Perlas y piel de azabache. El negro en las pesquerías de las Indias Occidentales.» Anuario de Estudios Americanos, vol. 65, n 2 (2008): 91-124.

Torres Merino, José Luis. Cubagua y su riqueza perlifera. Génesis del poblamiento de Suramérica. Madrid: Punto Rojo, 2018.

Warsh, Molly A. American Baroque. Pearls and the nature of Empire, 1492-1700. Chapel Hill: University of North Carolina press, 2018.

\section{Citar este artículo}

Herrera García, Francisco Javier. «Platería, perlas y negocios en la primera mitad del siglo XVI. Alonso de Oviedo y su protagonismo en la Sevilla americana y mercantil.» Historia Y MEMORIA, n 22 (2021): 359-395. DOI: https:/doi. org/10.19053/20275137.n22.2021.10988. 